Changes in disease activity and absolute remission rates after 3 and 6 months were calculated. Remission rates and change in disease activity from baseline were compared between JIA patients and a weighted RA cohort with weights based on age and gender, using linear and logistic regression for continuous and categorical variables, respectively.

Results: 281 JIA patients $(68.9 \%$ female, mean (SD) age 32.1 (11.1) years, mean (SD) diagnosis duration 23.5 (12.2) years) and 1374 RA patients $(71.6 \%$ female, mean (SD) age 52.7 (14.5) years, mean (SD) diagnosis duration 9.5 (10.0) years) were included in the analyses. Age, gender distribution and disease duration differed significantly between cohorts.

Both groups had a significant improvement across all disease activity measures after 3 months (Table 1), which was maintained after 6 months across all measures except MHAQ. The RA group had a significantly greater 3- and 6-month improvement in SJC28. Both groups had an overall 6-month increase in absolute remission rates. The JIA group had a significantly higher 3-month DAS28 remission rate (Figure 1). This difference was not significant after 6 months, as remission rates from 3 to 6 months in the JIA group declined across all measures.

Table 1.

\begin{tabular}{|c|c|c|c|c|c|c|c|c|c|}
\hline & \multicolumn{3}{|c|}{ Baseline } & \multicolumn{3}{|c|}{ Change to 3 months } & \multicolumn{3}{|c|}{ Change to 6 months } \\
\hline & $\mathrm{JIA}^{*}$ & $\mathbf{R A}^{*}$ & Diff. $\S$ & JIA* & $\mathbf{R A}^{*}$ & Diff. $^{\S}$ & JIA* & $\mathbf{R A}^{*}$ & Diff. ${ }^{\S}$ \\
\hline $\begin{array}{l}\mathrm{ESR}, \\
\mathrm{mm} / \mathrm{h}\end{array}$ & $\begin{array}{l}18.7 \\
(18.9)\end{array}$ & $\begin{array}{l}25.5 \\
(22.0)\end{array}$ & $\begin{array}{c}1.3(-2.3 \text { to } \\
4.9)\end{array}$ & $\begin{array}{l}-7.4 \\
(15.8)\end{array}$ & $\begin{array}{l}-7.6 \\
(16.6)\end{array}$ & $\begin{array}{r}-0.3(-4.4 \\
\text { to } 3.8)\end{array}$ & $\begin{array}{l}-7.4 \\
(16.8)\end{array}$ & $\begin{array}{l}-8.5 \\
(18.2)\end{array}$ & $\begin{array}{r}0.0(-5.7 \\
\text { to } 5.7)\end{array}$ \\
\hline SJC28 & $\begin{array}{l}2.5 \\
(3.6)\end{array}$ & $\begin{array}{l}5.5 \\
(5.4)\end{array}$ & $\begin{array}{c}1.6 \text { (1.3 to } \\
2.0)\end{array}$ & $\begin{array}{l}-1.4 \\
(3.4)\end{array}$ & $\begin{array}{l}-3.1 \\
(4.7)\end{array}$ & $\begin{array}{c}-1.0(-1.7 \text { to } \\
-0.3)\end{array}$ & $\begin{array}{l}-1.6 \\
(3.2)\end{array}$ & $\begin{array}{l}-3.5 \\
(5.1)\end{array}$ & $\begin{array}{c}-1.0(-1.9 \\
\text { to } \\
-0.1)\end{array}$ \\
\hline TJC 28 & $\begin{array}{l}4.0 \\
(5.6)\end{array}$ & $\begin{array}{l}6.6 \\
(6.4)\end{array}$ & $\begin{array}{c}1.3(0.4 \text { to } \\
2.3)\end{array}$ & $\begin{array}{l}-1.8 \\
(3.9)\end{array}$ & $\begin{array}{l}-3.1 \\
(5.9)\end{array}$ & $\begin{array}{c}-0.6(-1.4 \text { to } \\
0.2)\end{array}$ & $\begin{array}{l}0-1.8 \\
(3.9)\end{array}$ & $\begin{array}{l}-3.9 \\
(6.2)\end{array}$ & $\begin{array}{r}-1.0(-2.0 \\
\text { to } 0.1)\end{array}$ \\
\hline DAS28 & $3.6(1.4)$ & $4.5(1.6$ & $\begin{array}{c}0.3(0.1 \text { to } \\
0.6)\end{array}$ & $\begin{array}{l}-1.2 \\
(1.3)\end{array}$ & $\begin{array}{l}-1.2 \\
(1.4)\end{array}$ & $\begin{array}{r}-0.0(-0.3 \\
\text { to } 0.3)\end{array}$ & $\begin{array}{l}-1.2 \\
(1.3)\end{array}$ & $\begin{array}{l}-1.5 \\
(1.4)\end{array}$ & $\begin{array}{r}-0.2(-0.6 \\
\text { to } 0.2)\end{array}$ \\
\hline SDAI & $\begin{array}{l}16.8 \\
(10.6)\end{array}$ & $\begin{array}{l}23.1 \\
(14.3)\end{array}$ & $\begin{array}{c}2.4 \text { (0.3 to } \\
4.5)\end{array}$ & $\begin{array}{l}-7.7 \\
(9.9)\end{array}$ & $\begin{array}{l}-10.9 \\
(12.7)\end{array}$ & $\begin{array}{r}-2.0(-4.2 \\
\text { to } 0.2)\end{array}$ & $\begin{array}{l}-7.9 \\
(8.6)\end{array}$ & $\begin{array}{l}-13.2 \\
(13.6)\end{array}$ & $\begin{array}{r}-2.8(-5.8 \\
\text { to } 0.2)\end{array}$ \\
\hline PGA & $\begin{array}{l}51.4 \\
(26.3)\end{array}$ & $\begin{array}{l}49.9 \\
(25.5)\end{array}$ & $\begin{array}{r}-4.0(-8.5 \\
\text { to } 0.5)\end{array}$ & $\begin{array}{l}-20.6 \\
(26.7)\end{array}$ & $\begin{array}{l}-17.0 \\
(26.7)\end{array}$ & $\begin{array}{c}2.7(-2.2 \text { to } \\
7.6)\end{array}$ & $\begin{array}{l}-21.6 \\
(25.3)\end{array}$ & $\begin{array}{l}-19.1 \\
(28.7)\end{array}$ & $\begin{array}{r}3.4(-3.0 \\
\text { to } 9.8)\end{array}$ \\
\hline MHAQ & $\begin{array}{l}0.6 \\
(0.5)\end{array}$ & $\begin{array}{l}0.7 \\
(0.5)\end{array}$ & $\begin{array}{c}0.0(-0.1 \text { to } \\
0.1)\end{array}$ & $\begin{array}{l}-0.24 \\
(0.42)\end{array}$ & $\begin{array}{l}-0.22 \\
(0.42)\end{array}$ & $\begin{array}{c}0.0(-0.1 \text { to } \\
0.1)\end{array}$ & $\begin{array}{l}-0.23 \\
(0.40)\end{array}$ & $\begin{array}{l}-0.25 \\
(0.45)\end{array}$ & $\begin{array}{r}0.0(-0.1 \\
\text { to } 0.1)\end{array}$ \\
\hline
\end{tabular}

${ }^{\star}$ Mean $(\mathrm{SD})^{\S}$ Weighted group difference, RA coefficient (95\% confidence interval)

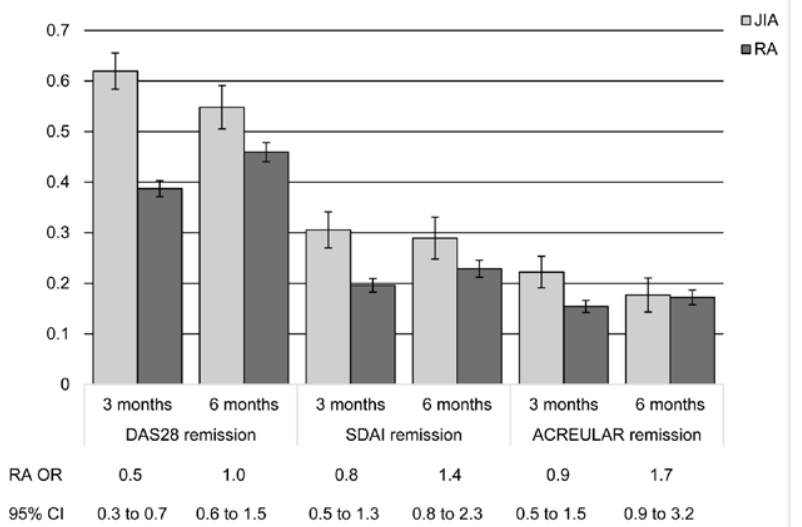

Figure 1. Mean 3- and 6-month remission rates with error bars (SE)

Conclusion: TNFi was equally effective in reducing disease activity in the JIA and RA cohort after 3 and 6 months, and in inducing remission after 6 months. Absolute remission rates in the JIA group declined from 3 to 6 months across all measures, and studies with longer duration are needed to explore the long-term efficacy of TNFi in the patient groups.

REFERENCES:

[1] Kvien, T.K., et al., A Norwegian DMARD register: prescriptions of DMARDs and biological agents to patients with inflammatory rheumatic diseases. Clin Exp Rheumatol, 2005. 23(5 Suppl 39): p. S188-94.

Disclosure of Interests: Imane Bardan: None declared, Karen Minde Fagerli: None declared, Joe Sexton: None declared, Gunnstein Bakland Speakers bureau: Abbvie, Consultant of: UCB, Pfizer, Novartis, Pawel Mielnik: None declared, Liz Marina Paucar Loli: None declared, Tore K. Kvien Speakers bureau: Fees for speaking: Amgen, Celltrion, Egis, Evapharma, Ewopharma, Hikma, Oktal, Sandoz, Sanofi, Consultant of: Fees for consulting: AbbVie, Amgen, Biogen, Celltrion, Eli Lilly, Gliead, Mylan, Novartis, Pfizer, Sandoz, Sanofi, Grant/ research support from: Received research funding to Diakonhjemmet Hospital from Abbvie, Amgen, BMS, MSD, Pfizer and UCB, Eirik kristianslund: None declared, Anna-Birgitte Aga Grant/research support from: Dr. Aga reports personal fees from Abbvie, Eli Lilly, Novartis and Pfizer, outside the submitted work DOI: 10.1136/annrheumdis-2021-eular.1708

\section{POS1306 TREATMENT STRATEGIES IN CHRONIC RECURRENT MULTIFOCAL OSTEOMYELITIS (CMRO) OR CHRONIC NON-BACTERIAL OSTEOMYELITIS (CNO): SYSTEMATIC REVIEW AND META-ANALYSIS}

R. Dos-Santos ${ }^{1}$, C. Gomez-Vieites ${ }^{1}$, D. Fernández Fernández ${ }^{1}$, I. González Fernández ${ }^{1}$, A. Souto Vilas ${ }^{1}$, E. Perez-Pampín ${ }^{1}$, A. Mera Varela ${ }^{1} .{ }^{1}$ Clinical University Hospital in Santiago de Compostela, Rheumatology Department, Santiago de Compostela, Spain

Background: Glucocorticoids (GC), bisphosphonates (BP), non-steroida anti-inflammatory drugs (NSAID) and classical synthetic or biological disease-modifying antirheumatic drugs (cs/bDMARD) have been employed in the treatment of chronic recurrent multifocal osteomyelitis (CRMO) or chronic non-bacterial osteomyelitis (CNO). ${ }^{1,2}$ This one is a rare bone childhood illness and none treatment guidelines have been carried out till present. ${ }^{3}$

Objectives: To asses which treatment schedule employed in CRMO had the best response rates and try to expose a treatment recommendation.

Methods: A systematic literature review was made using Medline, Embase, Cochrane library and the Web of Science databases. The search strategy focused on synonyms of CRMO. A prevalence meta-analysis was performed to evaluate each treatment response. Stata 15.1 was used to perform statistical analysis.

Results: The search identified 1883 articles, of which 43 were finally selected. Complete response rate reached with NSAIDs was acceptable $[50 \%$ (Cl95\% 40-60)]. Lower response rates were reached by GC treatment [44\% (Cl95\% 25-63)] or csDMARD [38\% (CI95\% 28-48)]. The best complete response rates were reached by bDMARD and BP treatments [69\% (CI95\% 56-82) and $73 \%$ (Cl95\% 62-84), respectively].

Conclusion: This review and meta-analysis supports, taking into account its remission rates and its risk-benefit profile, NSAIDs as potential first-line agents in CRMO treatment. bDMARD and BP have reached the higher remission rates, turning into helpful treatment alternatives. There is not any treatment guidelines driving CRMO patients, but this analysis could help to select a suitable agent for each patient. Decision-making should be individualized.

\section{REFERENCES:}

[1] Wipff J, Costantino F, Lemelle I, et al. A large national cohort of French patients with chronic recurrent multifocal osteitis. Arthritis \& Rheumatol. 2014;67(4):1128-1137.

[2] Zhao Y, Wu EY, Oliver M S, et al. Consensus treatment plans for chronic nonbacterial osteomielitis refractory to nonsteroideal anti-inflammatory drugs and/or with active spinal lesions. Arthritis Care Res. 2018;70(8):1228-1237.

[3] Menashe SJ, Aboughalia $\mathrm{H}$, Zhao $\mathrm{Y}$, et al. The many faces of pediatric chronic recurrent multifocal osteomyelitis (CRMO): a practical location- and case-based approach to differenciate CRMO from its mimics. J Magn Reson Imaging. 2020;e27299.

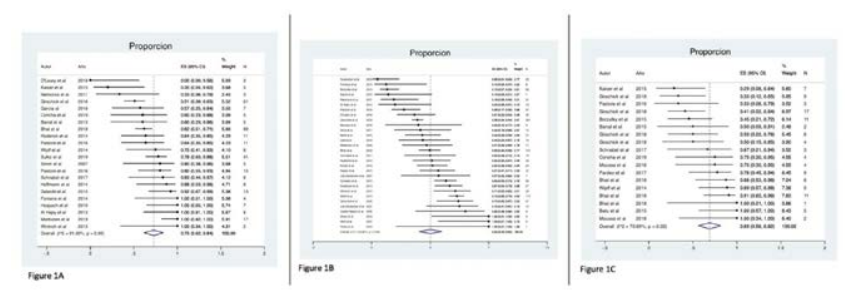

Disclosure of Interests: None declared DOI: 10.1136/annrheumdis-2021-eular.1890

\section{POS1307 ULTRASOUND-DETECTED TENOSYNOVITIS IN ANKLES WITH CLINICALLY ACTIVE DISEASE OF CHILDREN WITH NEW-ONSET JUVENILE IDIOPATHIC ARTHRITIS DOES NOT AFFECT THE CHANCE TO ACHIEVE DISEASE REMISSION}

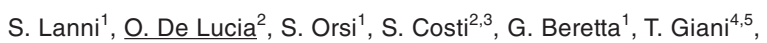
G. Filocamo ${ }^{1}$, C. V. Agostoni ${ }^{1,3}$, R. Cimaz ${ }^{3,6}$ on behalf of PRAGMA (Pediatric Rheumatology Associated Group of the Milan Area). ${ }^{1}$ Fondazione IRCCS Ca' Granda Ospedale Maggiore Policlinico di Milano, Milano, Italy, Paediatrics, Milano, Italy; ${ }^{2}$ Clinical Rheumatology Unit, ASST Centro Traumatologico Ortopedico G. Pini-CTO, Milano, Italy, Department of Rheumatology and Medical Sciences, Milano, Italy; ${ }^{3}$ University of Milano, 
Italy, Department of Clinical Sciences and Community Health, Milano, Italy; ${ }^{4}$ AOU Meyer, Florence, Italy, Paediatrics, Firenze, Italy; ${ }^{5}$ University of Siena, Siena, Italy, Department of Medical Biotechnology, Siena, Italy; ${ }^{6}$ Pediatric Rheumatology Unit, ASST Centro Traumatologico Ortopedico G. PiniCTO, Milano, Italy, Department of Rheumatology and Medical Sciences, Milano, Italy

Background: The ankle is one of the most commonly affected sites in juvenile idiopathic arthritis (JIA). This region has a complex anatomical structure owing to the presence of multiple joint recesses and surrounding tendons. While the prognostic value of ultrasound (US)-detected arthritis has been investigated in recent studies, the role of tenosynovitis in JIA remains still unexplored.

Objectives: To investigate: 1) US features of ankle involvement in JIA at disease onset; 2) the predictive value of US-detected tenosynovitis in ankles with clinically active disease of children with new-onset JIA.

Methods: The clinical charts of all consecutive patients with new-onset JIA between May 2018 and January 2020 at study centres (Policlinico and G.Pini Hospitals of Milan) and with clinically active ankle disease among the joints affected were reviewed retrospectively. Data on ankle US assessment were retrieved and patients were then stratified as follows: 1) patients with detection on US of isolated arthritis in at least one of the joint recesses of the ankle region; 2) patients with detection on US of tenosynovitis in at least one of the tendon compartments of the ankle irrespective of the presence of concomitant arthritis. For each of these two categories, estimation of patients who were able to achieve clinical disease remission at 12 months since disease onset was evaluated.

Results: Twenty-seven new-onset JIA patients were found to have clinical involvement of the ankle among the joints affected. Nine of them (33.3\%) showed on US isolated arthritis of the ankle, whereas US-detected tenosynovitis was found in $18(66.7 \%)$ patients. The amount of patients who were able to achieve disease remission at 12 -months was the same $(66.7 \%)$ for both patients with and without US-detected tenosynovitis in the ankle (12/18 and 6/9 patients, respectively). In patients with US-detected tenosynovitis and clinical disease remission at 12 months, the lateral tendon compartment (LTC) was the tendon site more frequently affected by pathology $(75.0 \%)$. Patients with US-detected tenosynovitis that did not achieve clinical disease remission at follow-up had the highest frequency of tendon pathology on US in the medial tendon compartment (MTC) (83.3\%). The anterior tendon compartment was the less frequently affected tendon compartment of the ankle in all patients (33.3\% in both patients with and without clinical remission of disease at the 12-months follow-up visit).

Conclusion: US-detected tenosynovitis of the ankle is a common finding in patients with new-onset JIA with clinically ankle disease activity and is more frequent than the detection on US of isolated arthritis. The MTC and LTC are the tendon compartments more commonly affected on US. The detection on US of tenosynovitis at disease onset in ankles with clinical disease activity did not seem to affect the change to achieve the overall clinical disease remission compared to patients without tendon pathology but with joint disease in the ankle region.

Disclosure of Interests: None declared

DOI: 10.1136/annrheumdis-2021-eular.1931

\section{POS1308 \\ PREDICTORS OF DISEASE PROGRESSION IN A MONOCENTRIC COHORT OF 100 PATIENTS WITH CHILDHOOD-ONSET SYSTEMIC LUPUS ERYTHEMATOSUS}

C. Chighizola ${ }^{1,2}$, I. Pontikaki ${ }^{2}$, S. Costi ${ }^{1,2}$, G. Armentaro ${ }^{1,2}$, M. Gattinara ${ }^{2}$, T. Giani ${ }^{3}$, R. Cimaz ${ }^{1,2,4} .{ }^{1}$ University of Milan, Department of Clinical Sciences and Community Health, Milan, Italy; ${ }^{2}$ ASST G. Pini \& CTO, Pediatric Rheumatology Unit, Milan, Italy; ${ }^{3}$ Azienda Ospedaliero Universitaria Meyer, Rheumatology, Florence, Italy; ${ }^{4}$ University of Milan, RECAP_RD, Milan, Italy

Background: Childhood-onset systemic lupus erythematosus (CSLE) accounts for $10-20 \%$ of overall cases, usually presenting in early adolescence. SLE in children is characterized by a severe clinical course.

Objectives: This study describes the evolution of clinical manifestations of CSLE, with the aims of i) identifying biomarkers predictive of disease progression and ii) assessing the effects of treatment on disease course.

Methods: Laboratory and clinical data of CSLE patients followed in our Paediatric Rheumatology Unit were retrospectively collected at diagnosis and during follow-up. Continuous data were expressed as median (interquartile range [IQR]) and categorical data as percentages. The association between categorical variables was assessed by chi-squared test, the correlation between variables was tested by Pearson's test. Univariate linear regression analyses were performed to investigate the relationship between the rate of new disease manifestations at follow-up and candidate predictors. Statistical analysis was performed using GraphPadPrism v6. P values $<0.05$ were regarded statistically significant.

Results: One-hundred patients (89\% of female gender) with cSLE were included in this study, with a median age at disease onset of 13 years (10.515). Clinical details are presented in Table 1. Complement levels were reduced in 71 patients (C3 in 62 and C4 in 65). At a median follow-up of 118 months (57-239), the disease progressed in 93 patients, with a median of two new manifestations per patient (1-3). No correlation emerged between the number of new disease manifestations and both age at diagnosis and disease duration. Among serological biomarkers, a reduction in complement fractions at diagnosis emerged as the only predictor of new clinical manifestations due to CSLE ( $p=0.013$ for low $\mathrm{C} 3$ and $p=0.0004$ for low $\mathrm{C} 4$ ). Among the several different pharmacological tools, hydroxychloroquine (HCQ, $p=0.021,95 \%$ confidence interval (Cl) 0.0084-0.1007), azathioprine (AZA, $p=0.0217,95 \% \mathrm{Cl} 0.013-$ 0.1703 ) and cyclophosphamide (CTX, $p=0.0305,95 \% \mathrm{Cl} 0.013-0.170$ ) were identified as protective.

At follow-up, patients most commonly developed new haematological and cutaneous involvements, which were diagnosed in 43 and 11 patients, respectively. A trend towards statistical significance emerged for low $\mathrm{C} 4 \mathrm{lev}-$ els to predict new haematological involvement at follow-up ( $p=0.064$, chisquared: 3.42). Differently, positivity for antibodies against dsDNA emerged as the only predictor of the onset of cutaneous manifestations during follow-up ( $p=0.022$, chi-squared: 7.62). Low C3 levels approached statistical significance in the prediction of skin involvement $(p=0.058$, chi-squared 5.68).

Conclusion: According to the data from our monocentric cohort of 100 patients, complement and anti-dsDNA antibodies are the most accurate tools to predict disease progression in CSLE. HCQ, AZA and CTX reduce the rate of disease progression.

Table 1. Clinical manifestations, laboratory features and treatment details of recruited patients at diagnosis.

Number of patients

Skin manifestations

Skin manifestations
Haematological involvement

Lupus nephritis

Musculoskeletal involvement

Serositis

Neuropsychiatric involvement

Anti-nuclear antibodies

Anti-Ro antibodies

Anti-Sm antibodies

Anti-dsDNA antibodies

Anti-phospholipid antibodies

Hydroxychloroquine

Azathioprine

Cyclophosphosphamide

Micophenolate mofetil

Cyclosporine

Rituximab

Belimumab

Steroids

44

51

16
72

72
14

14

90

90
11

11
13

67
29

29

40

40
29

13
15

15

Disclosure of Interests: None declared

DOI: 10.1136/annrheumdis-2021-eular.2051

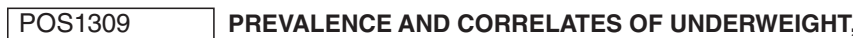 OVERWEIGHT AND OBESITY AMONG PATIENTS WITH JUVENILE IDIOPATHIC ARTHRITIS (JIA): EVIDENCE FROM THE NATIONAL PAEDIATRIC RHEUMATOLOGIC DATABASE (NPRD)}

F. Milatz ${ }^{1}$, J. Klotsche ${ }^{1}$, M. Niewerth ${ }^{1}$, J. Hörstermann ${ }^{1}$, D. Windschall ${ }^{2}$, F. Weller-Heinemann ${ }^{3}$, F. Dressler ${ }^{4}$, R. Berendes ${ }^{5}$, J. P. Haas ${ }^{6}$, G. Horneff ${ }^{7,8}$, K. Minden ${ }^{1,9} .{ }^{1}$ German Rheumatism Research Centre, Epidemiology and Health Care Research, Berlin, Germany; ${ }^{2}$ Northwest German Center for Rheumatology, Clinic of Paediatric and Adolescent Rheumatology, St.-JosefStift, Sendenhorst, Germany; ${ }^{3}$ Klinikum Bremen-Mitte, Prof.-Hess-Kinderklinik, Bremen, Germany; ${ }^{4}$ Children's Hospital, Medical School Hannover, Department of Paediatric Pneumology, Allergology and Neonatology, Hannover, Germany; ${ }^{5}$ Kinderkrankenhaus St. Marien, Paediatric Rheumatology, Landshut, Germany; ${ }^{6}$ German Center for Paediatric and Adolescent Rheumatology, Centre for Pain Therapy of Young People, Garmisch-Partenkirchen, Germany; ${ }^{7}$ Sankt Augustin Asklepios Children's Hospital, Division of Paediatric Rheumatology, Sankt Augustin, Germany; ${ }^{8}$ University Hospital of Cologne, Department of Paediatric and Adolescent Medicine, Cologne, Germany; ${ }^{9}$ Charité University 